\title{
TEMA 13-2014: Carcinoma Mucoepidermoide de Glándulas Salivales: una entidad clínica frecuente
}
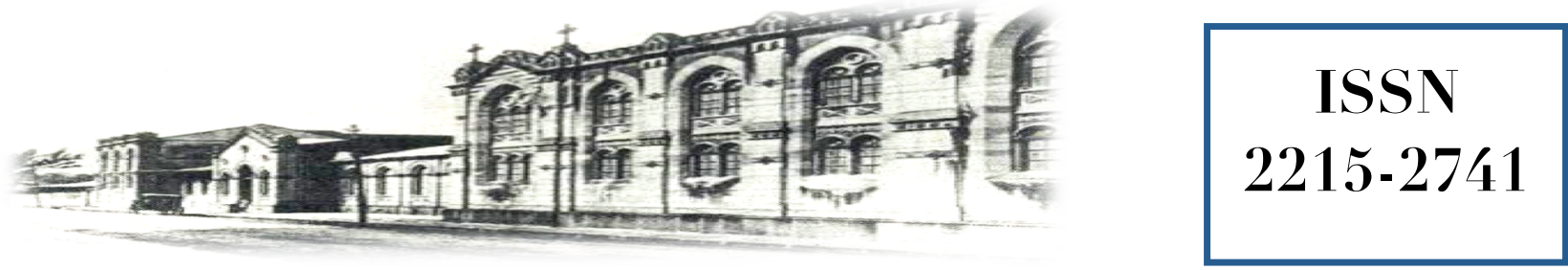

Recibido:

$23 / 03 / 2014$

Aceptado:

$24 / 04 / 2014$

\footnotetext{
${ }^{1}$ Médico General. Correo electrónico: irenevs14@gmail.com

${ }^{2}$ Cirujano Maxilofacial. Hospital San Juan de Dios, San José, Costa Rica. Correo electrónico: gusvarso@gmail.com
}

Irene Vargas Soto ${ }^{1}$ Gustavo Vargas Soto ${ }^{2}$

\section{RESUMEN}

El carcinoma mucoepidermoide es el tumor maligno de glándulas salivales más común tanto en adultos como en niños, puede presentarse en diferentes órganos como boca, faringe, laringe y glándula parótida, causando diferentes manifestaciones clínicas, desde aumento de volumen asintomático hasta síntomas inespecíficos como dolor, ulceración y sangrado. Como otros tumores, tiene influencia genética y alteraciones cromosómicas que lo favorecen. La clasificación histopatológica es un aspecto clave ya que determina el abordaje terapéutico como su pronóstico.

\section{PALABRAS CLAVE}

Glándulas salivales. Neoplasias. Carcinoma mucoepidermoide.

\begin{abstract}
The mucoepidermoid carcinoma is the most common malignancy of the salivary glands, in adults as in children. This tumor can be seen in different organs like mouth, pharynx, larynx and parotid gland, causing a different clinical features, either asymptomatic swelling or associated to nonspecific symptoms like pain, ulcerations and bleeding. Like other tumors, it has genetic influence and chromosomal abnormalities that promotes it. The histopathological classification is a key to define the treatment plan and prognosis.
\end{abstract}

\section{KEY WORDS}

Salivary glands. Neoplasms. Mucoepidermoid carcinoma. 


\section{INTRODUCCIÓN}

El carcinoma mucoepidermoide (CME) es el tumor maligno más común de las glándulas salivales del tracto aerodigestivo aéreo y el árbol bronquial. Es un tumor con gran heterogeneidad celular que posee células productoras de mucina y células epidermoides. El comportamiento y manejo de estos tumores se basa en la influencia de los parámetros usuales como edad del paciente, estadío y grado de la enfermedad ${ }^{(1)}$.

La Organización Mundial de la Salud en una clasificación de 1991, después de una revisión sistemática de la histología, del grado de diferenciación y el comportamiento de esta neoplasia, recomendó que el término tumor mucoepidermoide fuera cambiado por carcinoma mucoepidermoide ${ }^{(2)}$.

\section{DISCUSIÓN}

\section{Epidemiología}

La incidencia global anual cuando se consideran todos los tumores glandulares, varía desde $0.4 \mathrm{a}$ 13.5 casos por una población de 100.000 individuos. La frecuencia de neoplasias salivares malignas varía entre 0.4 y 2.6 casos por 100.000 . En los Estados Unidos, los tumores malignos de glándulas salivales cuentan para el $6 \%$ de los casos de cáncer de cabeza y cuello y 0.3 de todos los casos de cáncer ${ }^{(3)}$.

Entre todos los tumores de glándulas salivales, el adenoma pleomorfo representa el $50 \%$ de ellos. El tumor de Warthin es el segundo en frecuencia. Existe un consenso, entre varias publicaciones, que el tumor maligno más frecuente de glándulas salivales es el carcinoma mucoepidermoide ${ }^{(3)}$.

Constituye un 5 a $10 \%$ de las neoplasias glandulares; sin embargo también se pueden encontrar en otros lugares como seno maxilar, laringe, faringe, entre otras. En la niñez, un 80 a $90 \%$ de las lesiones malignas de glándulas salivales está constituido por CME, carcinoma adenoide cístico y carcinoma de células $\operatorname{acinares}^{(4,5)}$.

$\mathrm{Su}$ incidencia es mayor en la segunda década de vida, aunque también se menciona una media de edad de 45 años. La mayoría de las neoplasias de paladar aparecen antes de los 40 años, mientras que por otro lado es raro en la primera década y edades avanzadas. Se conoce una predilección de sexo femenino en una relación de $3: 2^{(3)}$.

\section{Clasificación}

La proporción de diferentes células y su configuración arquitectónica varían entre tumores. El CME se ha clasificado en tres grados basado en sus criterios histológicos. Se toma en cuenta el porcentaje de componente quístico, la invasión perineural, la necrosis, cuatro o más mitosis por campo y presencia de anaplasia ${ }^{(3)}$.

I. CME de bajo grado: son bien demarcados, con áreas quísticas dilatadas conteniendo material mucinoso. Los quistes están formados por células mucinosas e intermedias.

II. CME de grado intermedio: la arquitectura tisular es sólida en lugar de quísica e irregular, con células intermedias predominando sobre las células productoras de mucina. Permanece un borde redondeado bien demarcado y ocasionalmente podría demostrar invasión perineural.

III. CME de alto grado: caracterizado por borde infiltrativo, anaplasia necrosis mitosis atípicas, invasión perineural y angiolinfática. Predominan células epidermoides pero pueden estar presentes células intermedias y mucinosas, con su mucina intracelular, lo cual distingue al CME del carcinoma epidermoide ${ }^{(6)}$.

La tinción de Mucicarmin y la técnica de PAS son frecuentemente usadas para distinguir las céulas productoras de mucina ${ }^{(6)}$.

\section{Bases Moleculares}

Como se ha descrito en estudios recientes, existe una relación entre alteraciones cromosómicas y el desarrollo carcinogénico. Se han identificado proximadamente 400 fusiones críticas de genes en cáncer. Estos oncogenes corresponden a un $20 \%$ de los cánceres humanos, incluyendo el CME. Se han visto implicadas, las alteraciones cromosómicas, en activación de protooncogenes o proteínas que facilitan el desarrollo 
carcinogénico. El CME está caracterizado por una traslocación del cromosoma $11 \mathrm{q}$ y $19 p$ resultando en una fusión entre los genes MECT1 y MAMLS2. Esta unión activa el elemento ligador de respuesta al adenosin monofosfato cíclico (CREB) y señales Notch que lleva como resultado la disrupción de los ciclos celulares y funciones de diferenciación. Como el CREB regula la proliferación y diferenciación celular, la deleción de MECT1 censura la actividad transformadora y se cree que esta disregulación causa tumorogénesis. Además, los genes Notch, como HES1 y HES5, tienen regulación positiva en las células tumorales del CME lo cual facilita, aún más, el desarrollo tumoral ${ }^{(1)}$.

En las últimas 3 décadas se ha visto un aumento en la incidencia de cáncer en orofaringe, con predominio en mujeres, el cual se propone es causado por el Virus del Papiloma Humano (HPV). Se ha demostrado un aumento en la incidencia de CME en mujeres entre 15 a 34 años, por lo que se propone que la carcinogénesis es mediada por el HPV de alto riesgo ${ }^{(7)}$.

En el estudio realizado por Isayeva y cols. para determinar el rol del HPV en el desarrollo de CME se demostró que este virus, por medio de la producción de oncoproteínas involucradas en el proceso de carcinogénesis, es común en este tipo de cáncer, principalmente los serotipos de alto riesgo. Se detectaron los serotipos HPV16 en $30 \%$ de los CME y el HPV18 en un $13 \%$, así como un $7 \%$ presentaba ambos serotipos. Se ha demostrado un aumento de la detección de HPV18 en la última década comparado con los diagnósticos hechos entre 1997 y el año 2000. A pesar de los estudios, no fue posible establecer una asociación entre el sitio del tumor y la infección por este virus. Se observó que la localización del HPV no está limitada únicamente a los componentes escamosos del CME, sino que también se encuentra en los elementos mucinosos y glandulares, lo cual es esperable debido a que los HPV de alto riesgo promueven adenocarcinomas cervicouterinos, incluyendo el CME uterino cervical que es $\operatorname{raro}^{(7)}$.

Es conocido que la infección por HPV de alto riesgo es responsable etiológicamente para una gama de carcinomas escamosos orofaríngeos. Los datos sugieren que la infección puede ser un promotor del CME, sin embargo, los resultados no demuestran relación causal. En este estudio, los autores deducen que la fusión de los genes MEC1 y MAML2 son eventos tempranos y, posiblemente la infección con HPV de alto riesgo promueve la carcinogénesis en pasos más $\operatorname{avanzados}^{(7)}$.

\section{Presentación Clínica}

El tumor se presenta firme y es la infamación no dolorosa el síntoma más frecuente, seguido por inflamación dolorosa, parestesia, dolor dental, paresia, trismus, fijación de nódulos linfáticos así como ulceración y sangrado. La mucosa puede tener un color rojo azulado. Puede haber erosión ósea. No se encontró correlación clínica entre los síntomas y signos y el grado histológico del tumor $^{(4)}$.

Los CME pueden encontrarse en diferentes estructuras, entre ellos la glándula parótida en un $50 \%, 7 \%$ en glándula submandibular y $1 \%$ en glándula sublingual. En glándulas salivales menores en un $45 \%$ principalmente en paladar y mucosa bucal ${ }^{(8)}$.

Las lesiones de bajo grado tienen áreas bien circunscritas, mientras que las lesiones de alto grado tienen márgenes no definidos e infiltran tejidos adyacentes. Estos tumores metastatizan principalmente a nódulos linfáticos, hueso $\mathrm{y}$ pulmón. En caso de CME de parótida, la infiltración perineural a través del curso del nervio facial en el segmento mastoideo del hueso temporal debe ser descartado ${ }^{(8)}$.

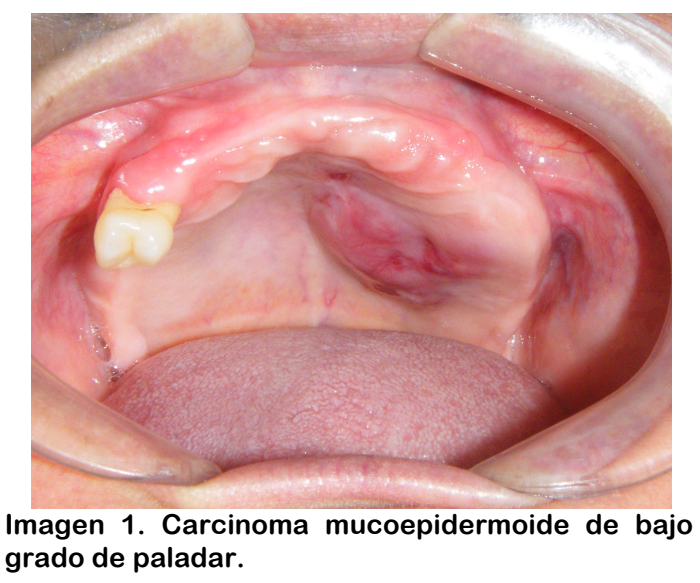

Imagen 1. Carcinoma mucoepidermoide de bajo grado de paladar. 


\section{Evaluación y Manejo}

La evaluación de un paciente con un tumor de glándulas salivales inicia con una historia clínica y examen físico exhaustivos. El único factor de riesgo aceptado para tumor de glándulas salivales es el antecedente de irradiación en cabeza y cuello; se ha propuesto la exposición a tabaco como factor de riesgo, sin embargo, no hay datos estadísticos que lo asocien. Posteriormente se deben realizar estudios de imágenes, en los cuales las radiografías simples se han abandonado debido a las grandes ventajas que traen otros estudios imagenológicos ${ }^{(9)}$.

Las masas en glándulas salivales, tanto malignas como benignas, tienen características similares en los estudios de imágenes como márgenes tumorales, homogeneidad e intensidad de la señal. Se sugiere malignidad cuando hay infiltración profunda en el espacio parafaringeo, músculos o hueso, propagación perineural; las cuales no se observan en lesiones benignas ${ }^{(8)}$.

Para una adecuada evaluación de la extensión y naturaleza del tumor se deben hacer estudios como ultrasonido de cuello, tomografía axial computarizada (TAC) o Resonancia Magnética Nuclear (RMN). El ultrasonido ayuda en el diagnóstico de la glándula salival, la valoración de ganglios cervicales así como en la toma de biopsia con aguja fina guiada por ultrasonido.

El TAC se utiliza principalmente para pacientes con sospecha de enfermedad inflamatoria, compromiso óseo o en pacientes con contraindicaciones para RMN. En este estudio se deben realizar tomas tanto con, como sin contraste para detectar calcificaciones, patrones de realce $y$ tomar en cuenta estructuras anatómicas.

La RMN es el método de elección en pacientes con masa palpable y alta sospecha de lesión neoplásica, ya que brinda información acerca de la localización exacta, extensión de la lesión, la invasión a estructuras vecinas, permite ver la invasión perineural y la infiltración meníngea ${ }^{(8)}$.

Un diagnóstico histopatológico certero se puede realizar mediante la aspiración con aguja fina con una excelente precisión, sensibilidad y especificidad. Otra forma útil es realizar una biopsia incisional tradicional ${ }^{(9)}$.
Es de amplio conocimiento que categorizar el grado de la neoplasia ayuda a la hora de decidir el manejo. Se plantea que tumores de bajo grado requieren únicamente manejo quirúrgico, mientras que los de alto grado van a recibir radiación adyuvante y disección de cuello. Existe controversia acerca del manejo del tipo intermedio $^{(10)}$.

En casos de tumores de glándulas salivales menores en el paladar, el manejo quirúrgico consiste en resecciones locales amplias, en ciertos casos inclusive se realiza hemimaxilectomia. Los defectos quirúrgicos son reconstruidos con colgajos locales o mediante transferencia de colgajos vascularizados, así como restauraciones protésicas. Esta última opción permite la vigilancia periódica de la cavidad del tumor para determinar recurrencia. Las lesiones malignas deben ser removidas completamente en un intento de dejar márgenes de tejido normal, debido a que las tasas de recurrencia son mayores en pacientes con márgenes positivos o en aquellos en que fueron primero positivos y después declarados negativos $^{(9)}$.

El manejo del cuello es un tema controversial. Algunos factores que usualmente indican que se debe realizar disección de cuello son el sitio y tamaño del tumor, el grado histológico y la edad del paciente. Se ha visto que los pacientes con baja probabilidad de encontrar nódulos positivos son los que tienen tumores de glándulas salivales menores en paladar duro, cavidad nasal, senos paranasales; mientras que los de riesgo intermedio se pueden encontrar en tumores de la cavidad oral y lengua. Los de alto riesgo son tumores de glándulas salivales menores de faringe y laringe ${ }^{(11)}$.

Los tumores parotídeos se extienden hacia los nódulos preauriculares adyacentes y luego a la región submandibular. Las neoplasiass de glándula submandibular se extienden a los nódulos submandibulares y cadena yugular superior, los tumores de labio invaden los ganglios submentales, mientras que los tumores intraorales metastatizan a los nódulos submandibular, postauriculares y nivel II. En casos avanzados hacia niveles III, IV y V. En cuanto a enfermedad a distancia se consideran pulmón, hígado, hueso y cerebro ${ }^{(3)}$. 
No está claro si el CME es un tumor radiosensible o radioresistente. Distintos autores han reportado experiencias con radioterapia aislada obteniendo buenos resultados en tumores en estadío temprano con enfermedad local. Basados en los reportes de casos, se ha visto que los tumores que mejor responden a radiación son los pobremente diferenciados ${ }^{(12)}$.

El rol de radioterapia adyuvante después de la cirugía es una forma de abordaje de estos tumores aunque es limitada por la localización. Radioterapia post cirugía actúa como un complemento, mejorando las tasas de control local en pacientes con márgenes quirúrgicos positivos. Por tanto, combinar la cirugía con radioterapia es el tratamiento principal para $\mathrm{CME}$ resecables $^{(12)}$.

Los avances tecnológicos en radioterapia permiten administrar altas dosis sin afectar los tejidos sanos circundantes; estas dosis altas han mostrado mejores resultados en tumores locales. Combinado, el uso de drogas radiosensibilizadoras con radioterapia tiene mejor control de distintos tumores. Por esto, radioquimioterapia es usado frecuentemente en enfermedad loco-regional avanzada en tumores de cabeza, cuello y nasofaringe. Quimioterapia como terapia única en cáncer de cabeza y cuello no ha visto efectos beneficiosos para CME. Cisplatino combinado con otros agentes quimioterapéuticos se han convertido en tratamiento estándar para manejo de metástasis $^{(12)}$.

\section{Pronóstico}

Se puede decir que no hay otro tumor de glándulas salivales en que el grado sea tan importante para pronóstico y tratamiento. Se reporta que la sobrevivencia a 5 años para $\mathrm{CME}$ varía entre un 92 y $100 \%$ para los de bajo grado, un 62 a 92\% para los de grado intermedio, y aproximadamente un 0 a $43 \%$ para los tumores de alto $\operatorname{grado}^{(10)}$.

McHugh y cols realizaron un estudio acerca del pronóstico de este tumor en 1500 pacientes con malignidad de glándulas salivales. Se encontró una sobrevivencia a los 5 años de $79 \%$, lo cual concuerda con la literatura, sin embargo aquellos con enfermedad avanzada tuvieron peor pronóstico. Se encontró que las características asociadas a mal pronóstico y menor supervivencia son: alto grado histológico, tumor de gran tamaño, enfermedad metastásica, invasión perineural y márgenes de resección positivos. En varios estudios se ha encontrado que la invasión perineural y el estadío de la enfermedad son factores pronósticos independientes $^{(13)}$.

Factores demográficos fueron evaluados para determinar pronóstico y el sexo tuvo un impacto significativo en la supervivencia y tiempo libre de enfermedad, teniendo el hombre un peor panorama en ambos aspectos, lo cual se podría asociar a una mayor edad, fumado, comportamiento y aumento de las comorbilidades en los pacientes masculinos; sin embargo, es necesario realizar más estudios para poder comprobar estos hallazgos ${ }^{(13)}$.

\section{CONCLUSIONES Y RECOMENDACIONES}

El carcinoma mucoepidermoide es el principal tumor maligno de glándulas salivales. Debe ser tomado en cuenta dentro de los posibles diagnósticos diferenciales, en pacientes con aumento de volumen de origen neoplásico en glándulas salivales mayores y menores.

Después de un adecuado estudio clínico e imagenológico, la biopsia es necesaria. Las características histológicas y su comportamiento son determinantes para clasificar este tumor y definir un plan de tratamiento. El CME de bajo grado tiene un pronóstico favorable mientras que el de alto grado se asocia a una menor tasa de sobrevivencia.

La RMN es el estudio de elección ante la sospecha de lesiones tumorales, dado que brinda mayor información sobre características y compromiso e invasión.

\section{REFERENCIAS BIBLIOGRÁFICAS}

1. Bell D El-Naggar A. Molecular Hetrogeneity in Mucoepidermoid Carcinoma: Conceptual and Practical Implications. Head and Neck Pathol. 2013;7:23-27.

2. Daryani D Gopakumar R Nagaraja, A. High-grade mucoepidermoid carcinoma of maxillary sinus. J Oral Maxillofac Pathol. 2012;16(1):137-140. 
3. Barnes L Eveson JW Reichart P Sidransky D. Pathology and Genetics of Head and Neck Tumours. World Health Organization. IARCPress Lyon, 2005

4. Kolude B Lawoyin J Akang E. Mucoepidermoid Carcinoma of the Oral Cavity. J Natl Med Assoc. 2001;93:178-184.

5. Ellies M Laskawi R. Diseases of the salivary glands in infants and adolescents. Head \& Face Medicine. 2010; 6:1-7.

6. Nance M Seethala $\mathrm{R}$ Wang $\mathrm{Y}$ et al. Treatment and Survival Outcomes Based on Histologic Grading in $\mathrm{Pa}$ tients with Head and Neck Mucoepidermoid Carcinoma. Cancer. 2008; 113(8):2082-2089.

7. Isayeva $\mathrm{T}$ Said-Al-Naief $\mathrm{N}$ Ren Z Li R Gnepp D Brandwein M. Salivary Mucoepidermoid Carcinoma: Demostration of Transcriptionally Active Human Papillomavirus 16/18. Head and Neck Pathol. 2013;7:135-148.

8. Thoeny H. Imaging of salivary gland tumors. Cancer Imaging. 2007;7:52-62.

9. Moore B Burkey B Netterville J Butcher B Amedee R. Surgical Management of Minor Salivary Gland Neoplasms of the Palate. The Ochsner Journal. 2008; 8:172-180.

10. Seethala R. An Update on Grading of Salivary Gland Carcinomas. Head and Neck Pathol. 2009;3:69-77.

11. Papadogeorgakis N Parara E Petsinis V Pappa E Nikolaidis A Alexandridis K. A Retrospective Review of Malignant Salivary Gland Tumors and a Proposed Protocol for Future Care. Craniomaxillofac Trauma Reconstruction. 2011; 4:1-10.

12. Martínez J Hervás A Montero A et al. Nasopharyngeal mucoepidermoid carcinoma: A case report and review of literature. Reports of Practical Oncology and Radiotherapy 2013;18:117-120.

13. McHugh C Roberts D El-Naggar A et al. Prognostic Factors in Mucoepidermoid Carcinoma of the Salivary Glands. Cancer. 2012;118:3928-3936.

\section{DECLARACIÓN DE CONFLICTO DE IN- TERESES}

Los autores declaran que no existen conflictos de intereses. 